\title{
Intraspecific variations in life history traits of two pecky rice bug species from Japan: mapping emergence dates and number of annual generations
}

Kazuhisa Yamasaki ${ }^{1}$, Ken Tabuchi $^{2}$, Akihiko Takahashi $^{3}$, Takeshi Osawa ${ }^{4}$, Akira Yoshioka ${ }^{5}$, Yasushi Ishigooka ${ }^{6}$, Shigeto Sudo $^{6}$, and Mayura TAKADA ${ }^{7}$

${ }^{1}$ Institute for Sustainable Agro-Ecosystem Services, Graduate School of Agricultural and Life Sciences, The University of Tokyo

${ }^{2}$ Division of Agro-Environment Research, Tohoku Agricultural Research Center, NARO

${ }^{3}$ Hokuriku Research Station, Central Region Agricultural Research Center, NARO

${ }^{4}$ Nanional Institute for Agro-Environmental Sciences

${ }^{5}$ Fukushima Branch, National Institute for Environmental Studies

${ }^{6}$ Institute for Agro-Environmental Sciences, National Agriculture and Food Research

Organization, NARO

${ }^{7}$ Chuo University Faculty of Science and Engineering Graduate School of Science and Engineering

January 11, 2021

\begin{abstract}
The mirid bugs Stenotus rubrovittatus and Trigonotylus caelestialium, which cause pecky rice, have become a threat to rice cultivation in Asia. Damage caused by these pests has rapidly become frequent since around 2000 in Japan. Their expansion pattern is not simple, making it difficult to manage them by prediction. Some insects with wide distributions have locally adapted variations in life-history traits. We performed laboratory rearing experiments to assess the geographical scale of intraspecific variations in life-history traits of S. rubrovittatus and T. caelestialium. These were aimed at increasing the accuracy of occurrence estimates and the number of generations per year. These results were compared with previous research, and differences in development rates were observed between populations of different latitudes, but not of the same latitude. Finally, plotting the timing of adult emergence and the potential number of generations per year on maps with a 5-km grid revealed that they differed greatly locally at the same latitude. These maps can be used for developing more efficient methods of managing mirid bugs in integrated pest management.
\end{abstract}

\section{Hosted file}

ManuscriptYamasekietal201217.pdf available at https://authorea.com/users/388800/articles/ 503536-intraspecific-variations-in-life-history-traits-of-two-pecky-rice-bug-speciesfrom-japan-mapping-emergence-dates-and-number-of-annual-generations 
T. caelestialium (previous studies)

$\square$ S. rubrovittatus (previous studies)

$\triangle$ Both species (present study)

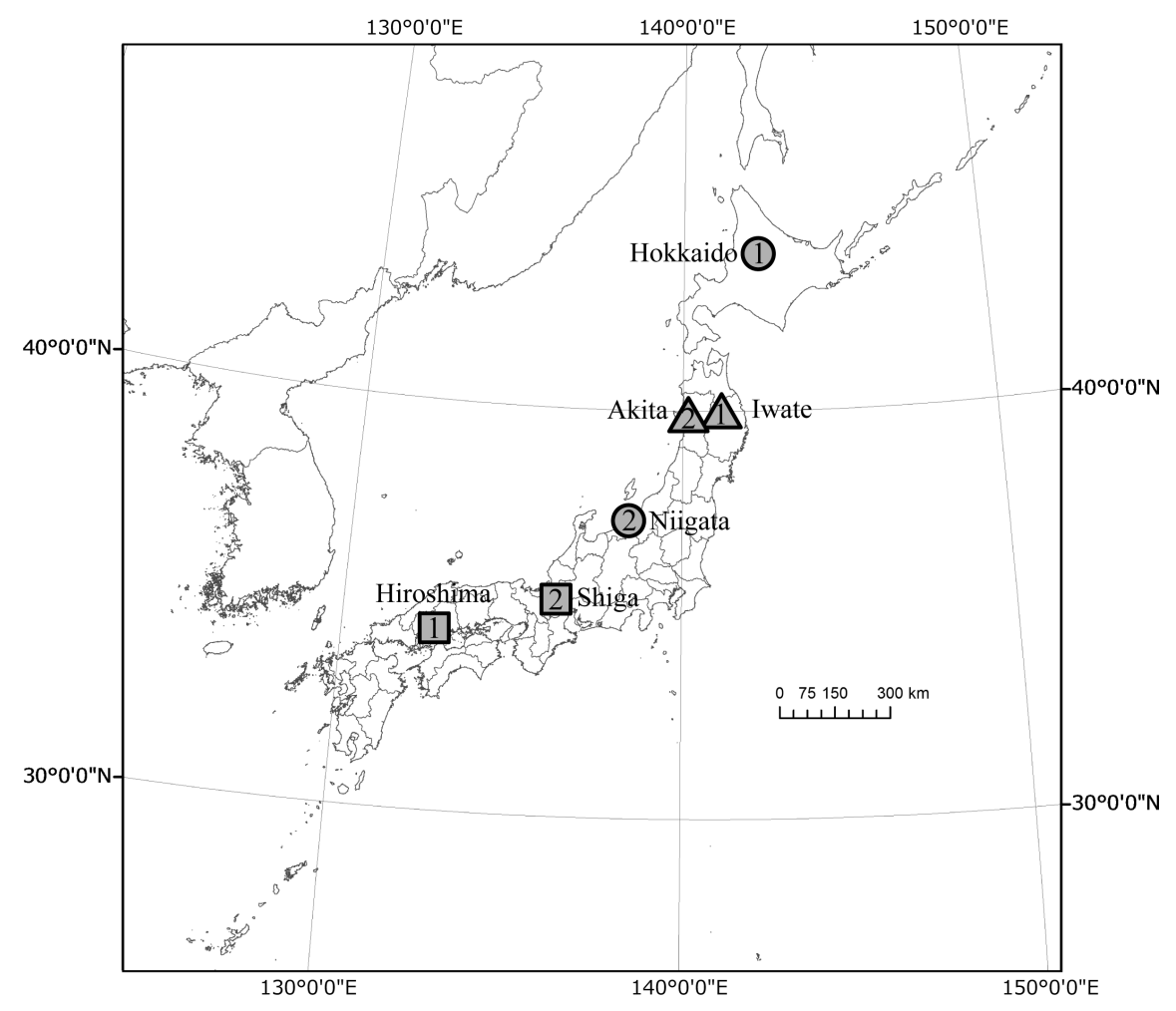


(a)
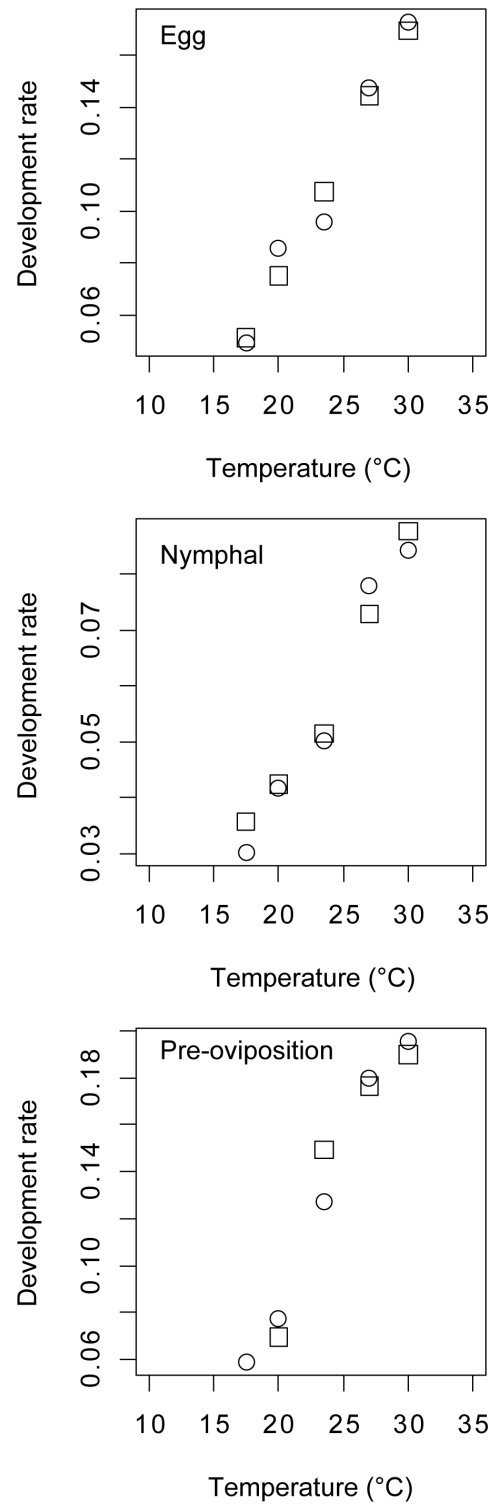

(b)
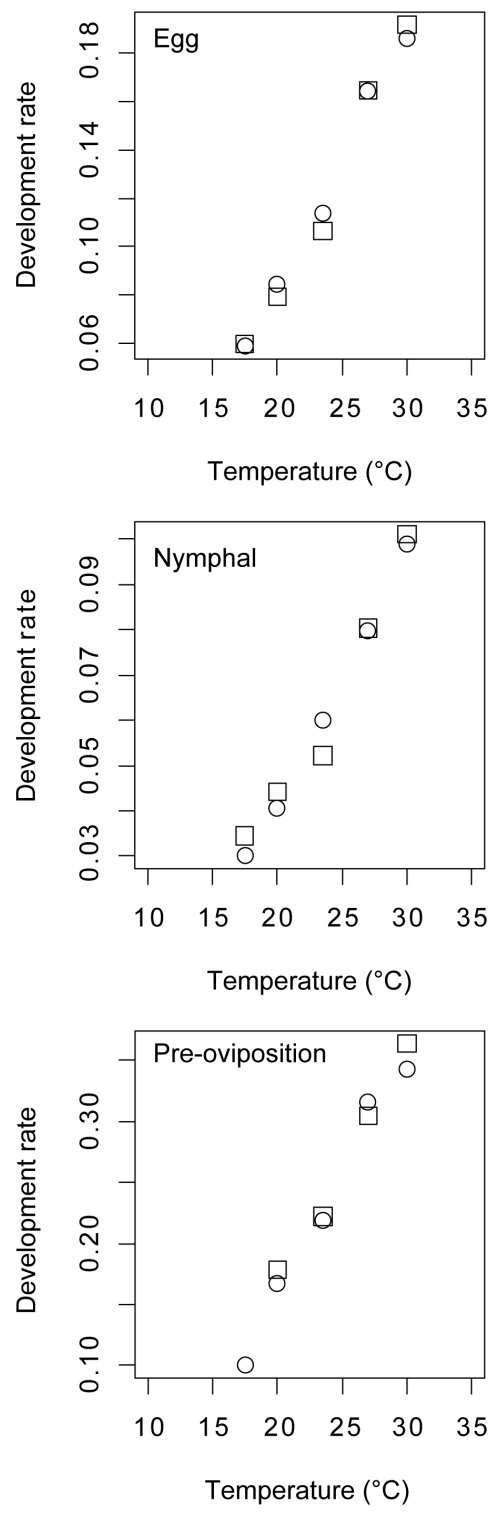
(a)
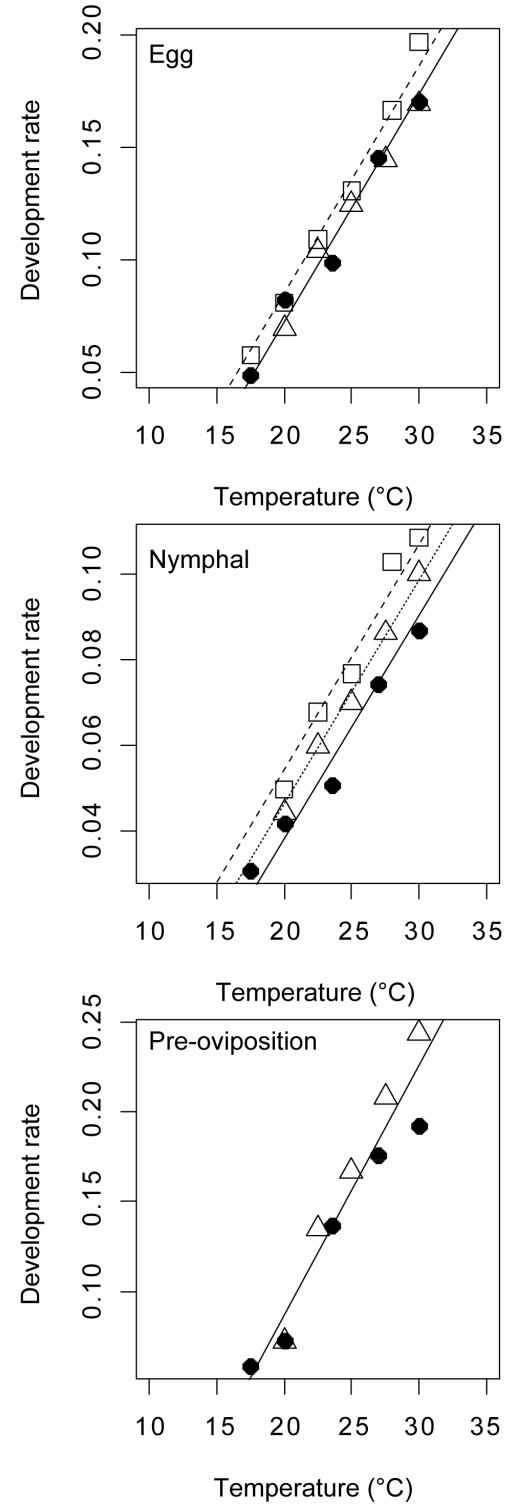

(b)
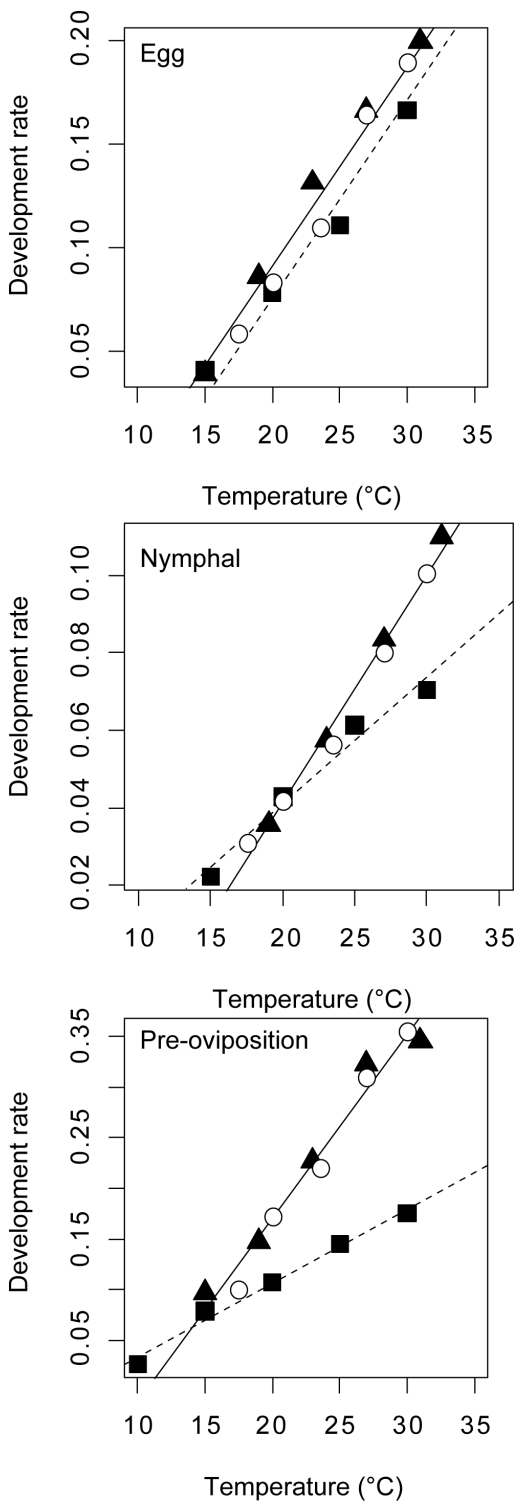


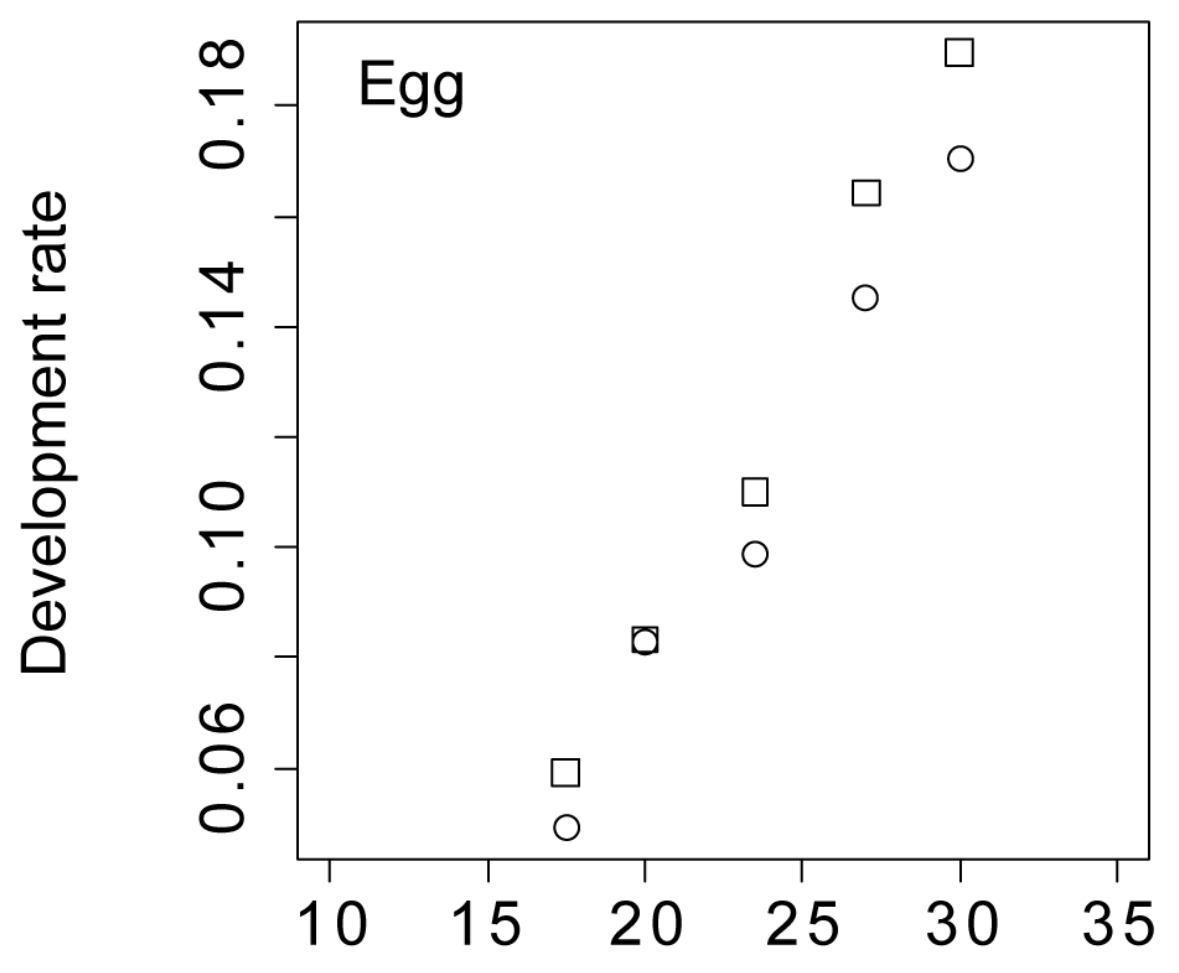

Temperature $\left({ }^{\circ} \mathrm{C}\right)$

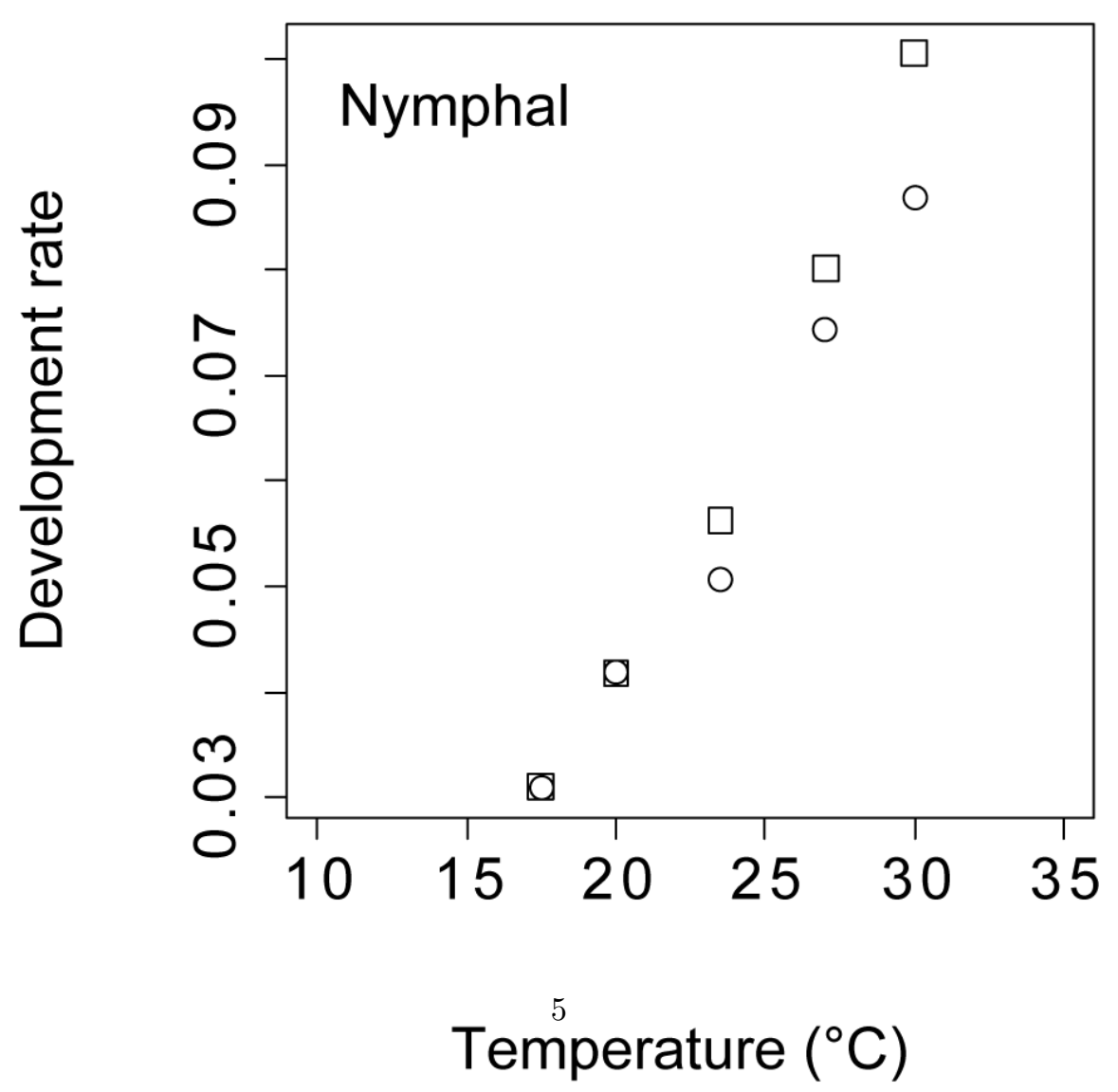

$\stackrel{n}{m}-\begin{array}{ll}\text { Pre-oviposition } & \square\end{array}$ 

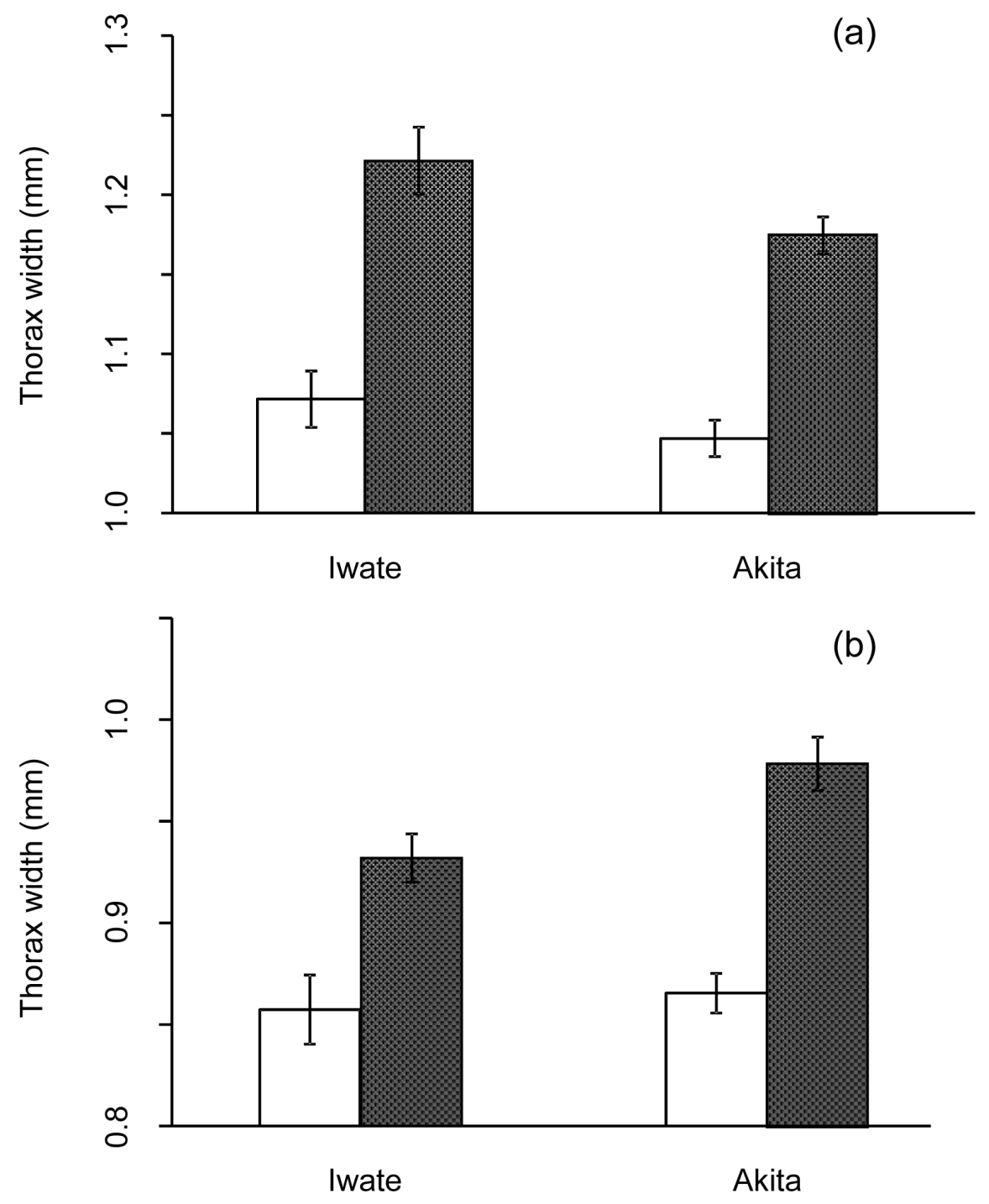

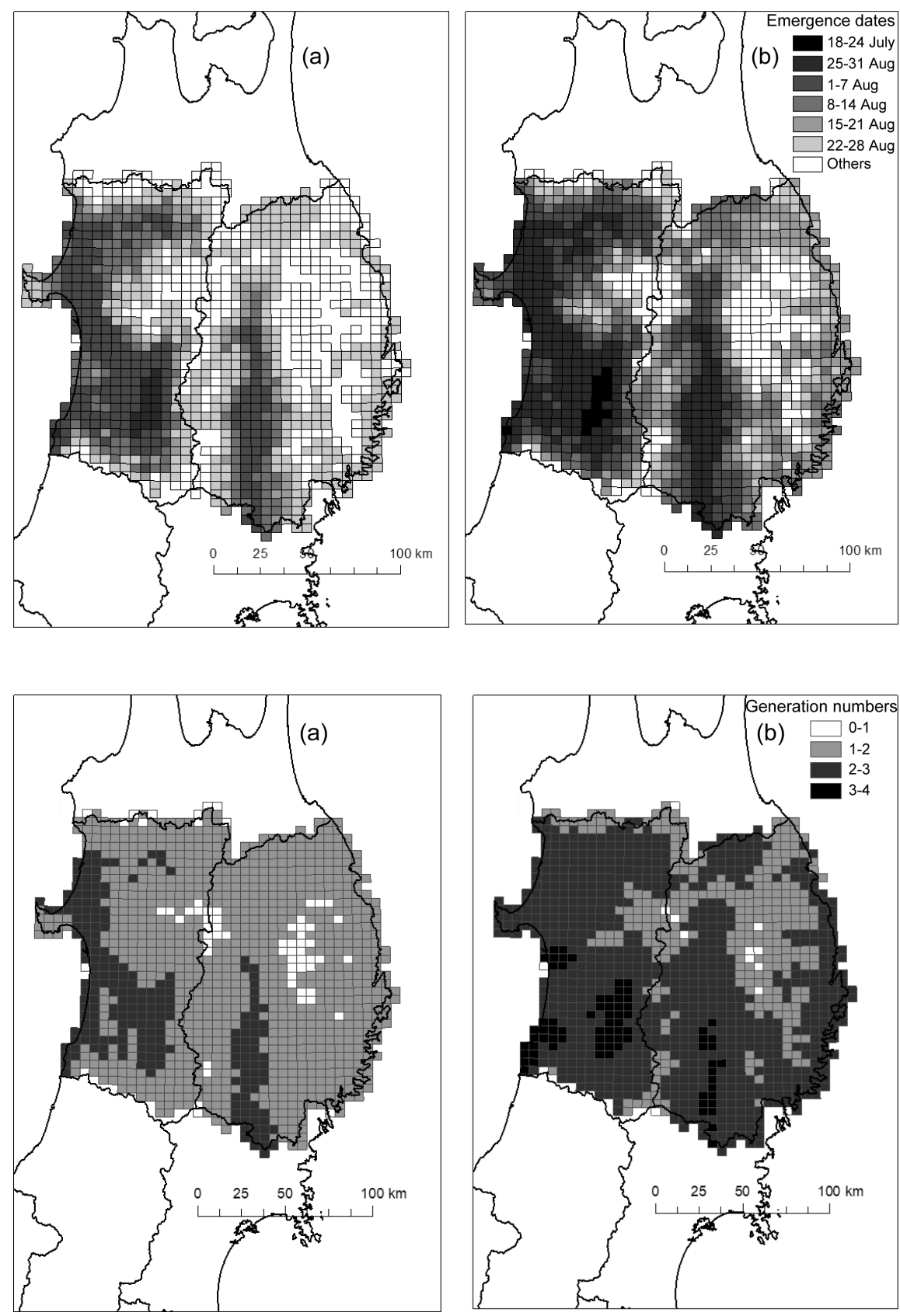